\title{
Pyrene Carboxylate Ligand Based Coordination Polymers for Microwave-Assisted Solvent-Free Cyanosilylation of Aldehydes
}

\author{
Anirban Karmakar ${ }^{1, *(\mathbb{D}}$, Anup Paul ${ }^{1}$ (D) Elia Pantanetti Sabatini ${ }^{1}$, M. Fátima C. Guedes da Silva ${ }^{1}$ (D) and \\ Armando J. L. Pombeiro 1,2,*iD \\ 1 Centro de Química Estrutural, Instituto Superior Técnico, Universidade de Lisboa, Av. Rovisco Pais, \\ 1049-001 Lisbon, Portugal; kanupual@gmail.com (A.P.); e.pantanettisabatini@studenti.unicam.it (E.P.S.); \\ fatima.guedes@tecnico.ulisboa.pt (M.F.C.G.d.S.) \\ 2 Peoples' Friendship University of Russia (RUDN University), 6 Miklukho-Maklaya Street, 117198 Moscow, \\ Russia \\ * Correspondence: anirbanchem@gmail.com (A.K.); pombeiro@tecnico.ulisboa.pt (A.J.L.P.)
}

Citation: Karmakar, A.; Paul, A.; Sabatini, E.P.; Guedes da Silva, M.F.C.; Pombeiro, A.J.L. Pyrene Carboxylate Ligand Based Coordination Polymers for Microwave-Assisted Solvent-Free Cyanosilylation of Aldehydes. Molecules 2021, 26, 1101. https: / / doi.org/10.3390/ molecules26041101

Academic Editors:

Catherine Housecroft and

Nikolay Gerasimchuk

Received: 20 January 2021

Accepted: 17 February 2021

Published: 19 February 2021

Publisher's Note: MDPI stays neutral with regard to jurisdictional claims in published maps and institutional affiliations.

Copyright: (c) 2021 by the authors. Licensee MDPI, Basel, Switzerland. This article is an open access article distributed under the terms and conditions of the Creative Commons Attribution (CC BY) license (https:// creativecommons.org/licenses/by/ $4.0 /)$.

\begin{abstract}
The new coordination polymers (CPs) $\left[\mathrm{Zn}\left(\mu-1 \kappa \mathrm{O}^{1}: 1 \kappa \mathrm{O}^{2}-\mathrm{L}\right)\left(\mathrm{H}_{2} \mathrm{O}\right)_{2}\right]_{\mathrm{n}} \cdot \mathrm{n}\left(\mathrm{H}_{2} \mathrm{O}\right)(\mathbf{1})$ and $\left[\mathrm{Cd}\left(\mu_{4}{ }^{-}\right.\right.$ $\left.\left.1 \kappa O^{1} \mathrm{O}^{2}: 2 \kappa N: 3,4 \kappa O^{3}-\mathrm{L}\right)\left(\mathrm{H}_{2} \mathrm{O}\right)\right]_{\mathrm{n}} \cdot \mathrm{n}\left(\mathrm{H}_{2} \mathrm{O}\right)(2)$ are reported, being prepared by the solvothermal reactions of 5-\{(pyren-4-ylmethyl)amino\}isophthalic acid $\left(\mathrm{H}_{2} \mathrm{~L}\right)$ with $\mathrm{Zn}\left(\mathrm{NO}_{3}\right)_{2} \cdot 6 \mathrm{H}_{2} \mathrm{O}$ or $\mathrm{Cd}\left(\mathrm{NO}_{3}\right)_{2} \cdot 4 \mathrm{H}_{2} \mathrm{O}$, respectively. They were synthesized in a basic ethanolic medium or a DMF: $\mathrm{H}_{2} \mathrm{O}$ mixture, respectively. These compounds were characterized by single-crystal X-ray diffraction, FTIR spectroscopy, thermogravimetric and elemental analysis. The single-crystal X-ray diffraction analysis revealed that compound 1 is a one dimensional linear coordination polymer, whereas $\mathbf{2}$ presents a two dimensional network. In both compounds, the coordinating ligand $\left(\mathrm{L}^{2-}\right)$ is twisted due to the rotation of the pyrene ring around the $\mathrm{CH}_{2}-\mathrm{NH}$ bond. In compound 1, the $\mathrm{Zn}$ (II) metal ion has a tetrahedral geometry, whereas, in $\mathbf{2}$, the dinuclear $\left[\mathrm{Cd}_{2}(\mathrm{COO})_{2}\right]$ moiety acts as a secondary building unit and the $\mathrm{Cd}(\mathrm{II})$ ion possesses a distorted octahedral geometry. Recently, several CPs have been explored for the cyanosilylation reaction under conventional conditions, but microwave-assisted cyanosilylation of aldehydes catalyzed by CPs has not yet been well studied. Thus, we have tested the solvent-free microwave-assisted cyanosilylation reactions of different aldehydes, with trimethylsilyl cyanide, using our synthesized compounds, which behave as highly active heterogeneous catalysts. The coordination polymer $\mathbf{1}$ is more effective than $\mathbf{2}$, conceivably due to the higher Lewis acidity of the $\mathrm{Zn}$ (II) than the $\mathrm{Cd}(\mathrm{II})$ center and to a higher accessibility of the metal centers in the former framework. We have also checked the heterogeneity and recyclability of these coordination polymers, showing that they remain active at least after four recyclings.
\end{abstract}

Keywords: coordination polymer; crystal structure analysis; heterogeneous catalysis; microwave; solvent-free; cyanosilylation reaction

\section{Introduction}

Coordination polymers are commonly viewed as a type of exceedingly popular functional materials because of their charming 1D, 2D and 3D architectures, in addition to their substantial utility in numerous applications, which include molecular sensing, gas storage and separation, etc. [1,2]. These materials can be deliberately designed to produce explicit structures, topologies and intriguing properties, which are of high demand [3].

Among various applications of the synthesized coordination polymers (CPs), catalysis is one of the most important and explored areas of research where they have been employed, often as heterogeneous catalysts [4-6]. This is largely due to their robustness and insoluble nature in most of the common organic solvents. The important organic transformations for which CPs have been developed and employed as heterogeneous catalysts include 
cyanosilylation of aldehydes or ketones [7], Knoevenagel condensation [8], oxidation of alkanes, alcohols or olefins [9], Henry reaction [10,11], ring-opening of epoxides [12], transesterification [13], cascade [14] reactions, etc.

Furthermore, in the domain of catalysis, cyanosilylation constitutes an important $\mathrm{C}-\mathrm{C}$ bond formation reaction, leading to cyanohydrins, which are regarded as a class of compounds with interest in chemistry and biology, being broadly applied for the synthesis of plenty of vital compounds, such as $\alpha$-hydroxy acids and aldehydes and $\beta$-amino alcohols [15]. Trimethylsilyl cyanide (TMSCN) is one of the mostly used reagents employed for the synthesis of cyanohydrins promoted by the presence of a Lewis acid or base catalyst, due to its facile use which proceeds via nucleophilic addition to carbonyl compounds to generate cyanohydrin trimethylsilyl ethers. Along these lines, the development of a powerful catalyst, which can effectively catalyze such a reaction is an important area of present-day research [16]. Although an array of complexes involving metal ions from d-, f- and p-blocks have been employed as catalysts for such a transformation [17-19], they mostly act in a homogeneous manner, and just a modest number of heterogeneous catalysts have been documented in this direction [20,21].

Other relevant features of a catalytic reaction concern the employed conditions. Although many of the catalytic reactions are being performed under conventional heating, there is an ever-increasing demand for an alternate energy source which will not only be cost-effective but also highly efficient and environmentally friendly. Microwave irradiation (MW) provides a notable technique which can take lesser time to perform a reaction, generate a better yield and selectivity, and is an ideal choice to look for. For a long time, our group has been utilizing this technique for carrying out many catalytic transformations [22]. Recently, various CPs have been explored for cyanosilylation of aldehydes under conventional conditions [23]; however, microwave-assisted cyanosilylation of aldehydes catalyzed by $\mathrm{CPs}$ has not yet been significantly studied. Thus, the exploration of appropriate $\mathrm{CP}$ based catalysts for the microwave-assisted solvent-free cyanosilylation of aldehydes is a topic of great interest.

In the current study, we synthesized the pro-ligand 5-\{(pyren-4-ylmethyl)amino\}isophthalic acid $\left(\mathrm{H}_{2} \mathrm{~L}\right)$ and constructed the one-dimensional $\left[\mathrm{Zn}\left(\mu-1 \kappa O^{1}: 1 \kappa O^{2}-\mathrm{L}\right)\left(\mathrm{H}_{2} \mathrm{O}\right)_{2}\right]_{n} \cdot \mathrm{n}\left(\mathrm{H}_{2} \mathrm{O}\right)(\mathbf{1})$ and the two-dimensional $\left[\mathrm{Cd}\left(\mu_{4}-1 \kappa O^{1} O^{2}: 2 \kappa N: 3,4 \kappa O^{3}-\mathrm{L}\right)\left(\mathrm{H}_{2} \mathrm{O}\right)\right]_{\mathrm{n}} \cdot \mathrm{n}\left(\mathrm{H}_{2} \mathrm{O}\right)(2)$ coordination polymers. They have been characterized by FTIR, thermogravimetric, elemental, and single-crystal and powder X-ray diffraction analyses. The insolubility and existence of both Lewis acid and basic (amine) centers in these CPs makes them favorable materials for bifunctional heterogeneous catalysis. Thus, we tested their heterogeneous catalytic activity towards the solvent-free microwave-assisted cyanosilylation reaction of different aldehydes under mild conditions.

\section{Results and Discussion}

\subsection{Synthesis and Characterization}

The solvothermal reaction of $\mathrm{H}_{2} \mathrm{~L}$ with $\mathrm{Zn}\left(\mathrm{NO}_{3}\right)_{2} \cdot 6 \mathrm{H}_{2} \mathrm{O}$ in ethanol and $\mathrm{NH}_{4} \mathrm{OH}$ leads to the formation of the coordination polymer $\left[\mathrm{Zn}\left(\mu-1 \kappa O^{1}: 1 \kappa O^{2}-\mathrm{L}\right)\left(\mathrm{H}_{2} \mathrm{O}\right)_{2}\right]_{\mathrm{n}} \cdot \mathrm{n}\left(\mathrm{H}_{2} \mathrm{O}\right)$ (1) $[\mathrm{L}=5-\{($ pyren-4-ylmethyl)amino\}isophthalate $]$. Upon performing the solvothermal reaction using $\mathrm{Cd}\left(\mathrm{NO}_{3}\right)_{2} \cdot 4 \mathrm{H}_{2} \mathrm{O}$ in the presence of DMF and water mixture, we obtained the coordination polymer $\left[\mathrm{Cd}\left(\mu_{4}-1 \kappa O^{1} O^{2}: 2 \kappa N: 3,4 \kappa O^{3}-\mathrm{L}\right)\left(\mathrm{H}_{2} \mathrm{O}\right)\right]_{n} \cdot \mathrm{n}\left(\mathrm{H}_{2} \mathrm{O}\right)(2)$ (Figure 1). In the FTIR spectra, the characteristic strong bands for the asymmetric stretching of coordinated carboxylate groups of $\mathbf{1}$ and $\mathbf{2}$ appear at $1640-1641 \mathrm{~cm}^{-1}$ and the symmetric stretching is observed at $1350-1370 \mathrm{~cm}^{-1}$. The $\mathrm{C}=\mathrm{C}$ stretching frequencies of the aromatic rings are present in the $1561-1572 \mathrm{~cm}^{-1}$ and $1411-1421 \mathrm{~cm}^{-1}$ regions. The band attributed to the secondary amine group can be found in the $2914-2934 \mathrm{~cm}^{-1}$ region. 


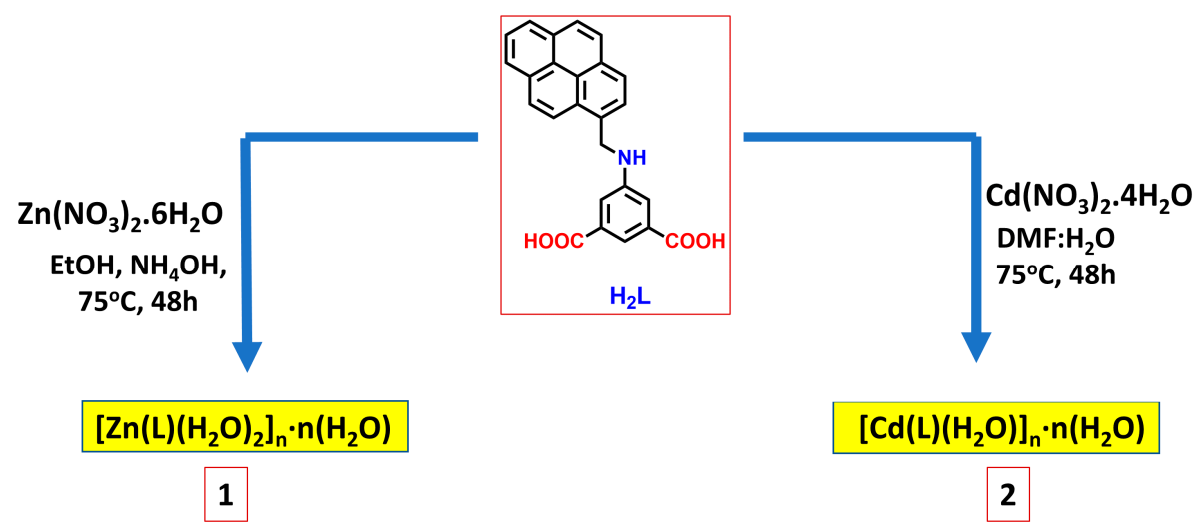

Figure 1. Synthesis of coordination polymers 1 and 2 by reactions of $\mathrm{H}_{2} \mathrm{~L}$ and $\mathrm{Zn}\left(\mathrm{NO}_{3}\right)_{2} \cdot 6 \mathrm{H}_{2} \mathrm{O}$ or $\mathrm{Cd}\left(\mathrm{NO}_{3}\right)_{2} \cdot 4 \mathrm{H}_{2} \mathrm{O}$, under solvothermal conditions.

\subsection{Thermogravimetric Analyses}

Thermogravimetric analyses were performed under dinitrogen from room temperature to ca. $800{ }^{\circ} \mathrm{C}$, with a heating rate of $5^{\circ} \mathrm{C} \mathrm{min}^{-1}$. Features of the thermal stability of the coordination polymers $\mathbf{1}$ and $\mathbf{2}$ are presented in Figure 2.

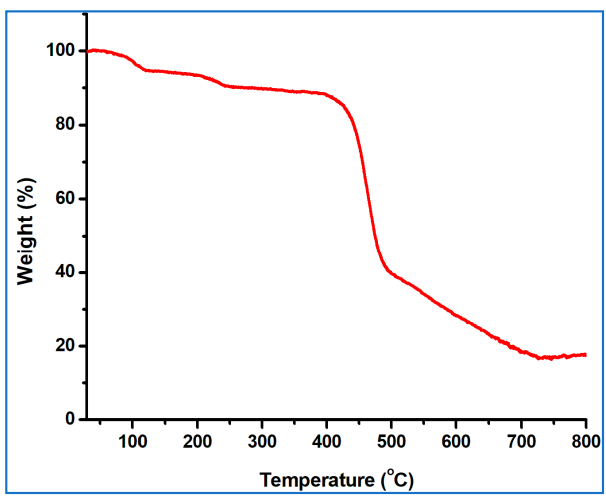

(A)

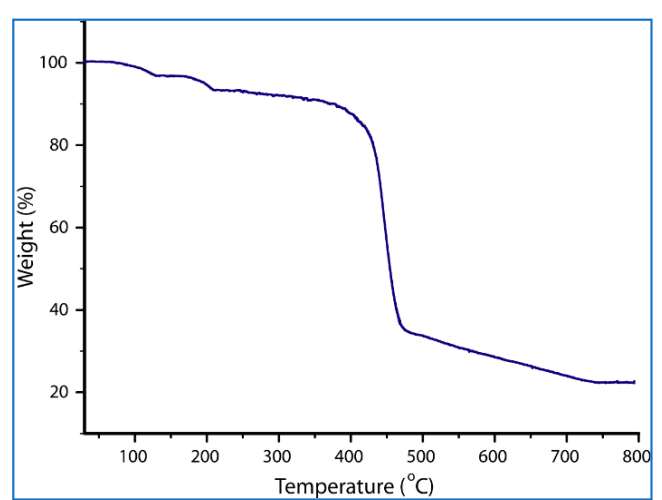

(B)

Figure 2. Thermogravimetric curves for $\mathbf{1}$ (A) and $\mathbf{2}$ (B).

The coordination polymer 1 shows a total weight decrease of $10.1 \%$ between 59 and $263{ }^{\circ} \mathrm{C}$, corresponding to the loss of the non-coordinated and coordinated water molecules (calcd: $10.5 \%$ ). Afterwards it remains stable up to $388^{\circ} \mathrm{C}$ and then starts to decompose until $739^{\circ} \mathrm{C}$ (Figure 2A). Compound 2 shows a weight loss of $3.1 \%$ in the $65-135^{\circ} \mathrm{C}$ temperature range, which is due to the removal of the non-coordinated water molecule (calcd: $3.5 \%$ ). In the temperature range of $136-210^{\circ} \mathrm{C}$, it loses the coordinated water molecule, equivalent to a weight loss of $3.2 \%$ (calcd: $3.5 \%$ ). However, above this temperature, the framework remains stable up to $364{ }^{\circ} \mathrm{C}$ and then starts to decompose until $745^{\circ} \mathrm{C}$ (Figure 2B).

\subsection{Crystal Structure Analysis}

The asymmetric unit of the coordination polymer 1 contains one zinc(II) ion, one $\mathrm{L}^{2-}$ ligand, two coordinated and one crystallization water molecules (Figure 3A,B). The Zn(II) center presents a distorted tetrahedral environment $\left(\tau^{4}=0.91\right)$ [24], and via the deprotonated $\mathrm{L}^{2-}$ ligand, it generates a $1 \mathrm{D}$ polymeric chain (Figure 3C). The metal ion binds two carboxylate oxygen atoms from two $\mathrm{L}^{2-}$ units [Zn1-O2 2.007(17) $\AA$ and Zn1-O3 1.970(16)

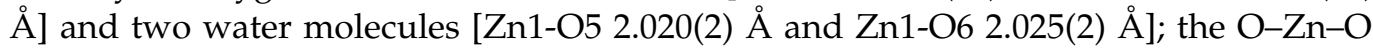
bond angles fall within the range of $103.0(7)^{\circ}$ to $119.7(9)^{\circ}$. The pyrene and isophthalate ring of the ligand are almost perpendicular with a dihedral angle of $73.34^{\circ}$. The observed non-planarity of the ligand is due to the relative twisting of the $\mathrm{CH}_{2}-\mathrm{NH}$ group, and the 
C4-N1-C9-C10 torsional angle is $163.21^{\circ}$. The carboxylate groups, working in a monodentate fashion, are nearly in the plane of the isophthalate ring (dihedral angles of $8.53^{\circ}$ and $12.92^{\circ}$ ). The distance between two symmetry related $\mathrm{Zn}$ (II) ions in a chain is $10.239 \AA$, which is considerably larger than the shortest intermolecular distance of $5.412 \AA$ between two metal ions in vicinal chains.

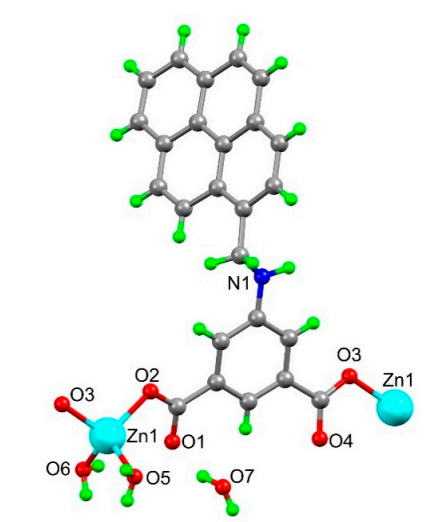

(n)

(B)

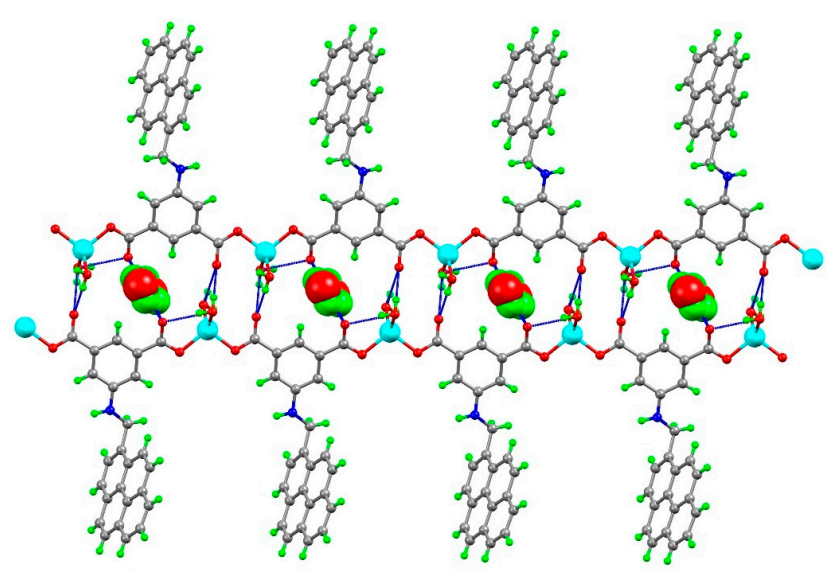

(C)

Figure 3. (A) Molecular structure of framework 1. (B) Schematic representation of framework 1. (C) Hydrogen bonded 1D chain of framework 1.

The 1D chains of coordination polymer $\mathbf{1}$ are hydrogen bonded through several O$\mathrm{H}$.... O interactions between the coordinated water molecules and the carboxylate-O atoms, forming a two-dimensional hydrogen bonded network. Moreover, these 2D hydrogen bonded networks are further connected via $\pi \cdots \pi$ interactions (between pyrene rings) with a distance of $3.489 \AA$ (Supplementary Materials Figure S1A), N-H $\cdots \pi \pi$ interactions (between amine $\mathrm{NH}$ and pyrene ring, $\mathrm{d}_{\mathrm{D}-\pi} 3.644 \AA$, Supplementary Materials Figure $\mathrm{S1B}$ ) and $\mathrm{C}-\mathrm{H} \cdots \pi \pi$ interactions (between pyrene $\mathrm{CH}$ and pyrene ring, $\mathrm{d}_{\mathrm{D}-\pi} 3.451 \AA$ ), which expand the structure to the third dimension.

The asymmetric unit of $\left[\mathrm{Cd}\left(\mu_{4}-1 \kappa O^{1} O^{2}: 2 \kappa N: 3,4 \kappa O^{3}-\mathrm{L}\right)\left(\mathrm{H}_{2} \mathrm{O}\right)\right]_{n} \cdot n\left(\mathrm{H}_{2} \mathrm{O}\right)(2)$ contains one $\mathrm{Cd}$ (II) ion, one $\mathrm{L}^{2-}$ ligand and one of each coordinated and non-coordinated water molecules (Figure 4A,B). The distorted octahedral coordination environment of $\mathrm{Cd}(\mathrm{II})$ ion is occupied by four carboxylate-O from three adjacent $\mathrm{L}^{2-}$ ligands [Cd1-O1 2.228(2), Cd1-O1' 2.451(3), Cd1-O3 2.343(2), Cd1-O4 2.401(3)] and one amine NH from a $\mathrm{L}^{2-}$ ligand [Cd1-N1 2.470(3)], and the remaining site is engaged with the water molecule [Cd1-O5 2.190(3)]. The $\mathrm{O}-\mathrm{Cd}-\mathrm{O}$ bond angles are within the range of $54.45(9)^{\circ}$ to $173.60(9)^{\circ}$. In this coordination polymer, the amine $\mathrm{NH}$ participates in the metal coordination, which we have not observed in other coordination polymers. The deprotonated $\mathrm{L}^{2-}$ ligand coordinates simultaneously to four metal ions, with two of them linked by a bridging-chelate carboxylate group, another one where carboxylate is in a chelate-monodentate mode, and the remaining one by the amine $\mathrm{NH}$ group. 


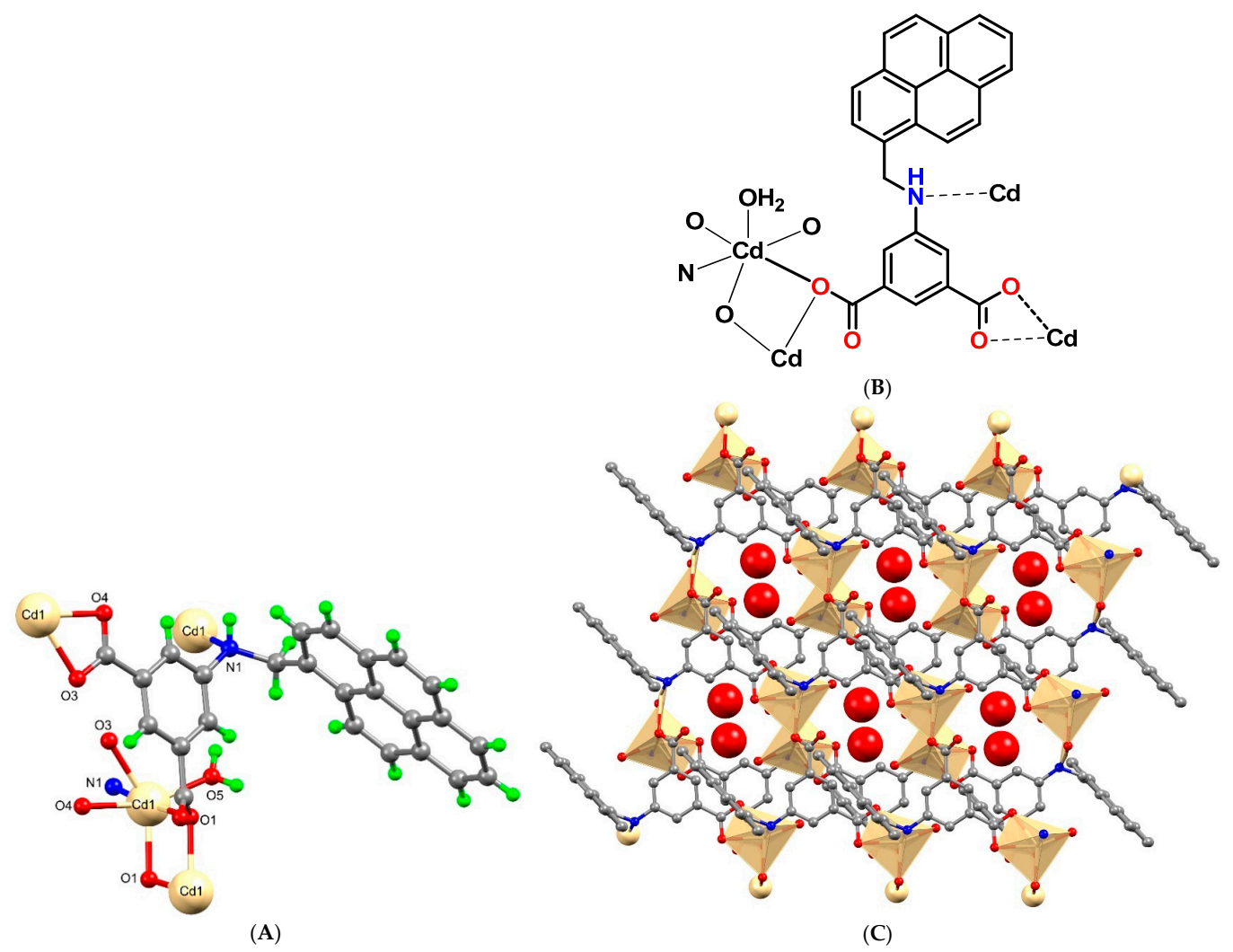

Figure 4. (A) Molecular structure of framework 2. (B) Schematic representation of framework 2. (C) Two-dimensional structure of framework $\mathbf{2}$ (the hydrogen-bonded water molecules are indicated as red balls).

As in 1, the organic ligand in $\mathbf{2}$ is highly twisted. The least-squares plane of the isophthalate ring makes a dihedral angle of $84.51^{\circ}$ with the pyrene ring and one of the carboxylate groups is $40.17^{\circ}$ twisted relatively to the plane of the aromatic ring it is attached to. The crystallographically related $\mathrm{Cd}$-ions are arranged in a dinuclear $\left[\mathrm{Cd}_{2}(\mathrm{COO})_{2}\right]$ cluster forming a secondary building block unit. The $\mathrm{Cd} \cdots \mathrm{Cd}$ distance within the dinuclear clusters is of $3.695 \AA$. Assembly of six $\mathrm{L}^{2-}$ ligands and the dinuclear $\left[\mathrm{Cd}_{2}(\mathrm{COO})_{2}\right]$ cluster results the construction of a two dimensional framework (Figure 4C). Moreover, the coordinated and non-coordinated water molecules are hydrogen bonded with carboxyl groups of the $\mathrm{L}^{2-}$ ligand through $\mathrm{O}-\mathrm{H} \cdots \mathrm{O}$ interactions. The amine $\mathrm{NH}$ is also engaged in a hydrogen-bonding interaction with carboxylate- $\mathrm{O}$ via $\mathrm{N}-\mathrm{H} \cdots \cdot \mathrm{O}$ interaction.

\subsection{Catalytic Activity Studies}

Taking advantage of the high thermal stability and insolubility in most of the common organic solvents of the coordination polymers $\mathbf{1}$ and $\mathbf{2}$, we tested them as heterogeneous catalysts for the cyanosilylation reaction of different aldehydes under microwave-assisted solvent-free conditions (Scheme 1). To begin with, benzaldehyde was taken as a model substrate, trimethylsilyl cyanide (TMSCN) as the silylating agent and the CP $\mathbf{1}$ or $\mathbf{2}$ as catalyst, and various reaction conditions like solvent, temperature and catalyst amount, were optimized. 


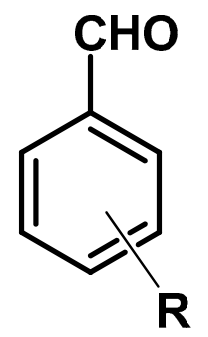

\section{Coordination polymer 1 or 2 \\ TMSCN, MW, $50^{\circ} \mathrm{C}, 1.5 \mathrm{~h}$ Solvent-Free}

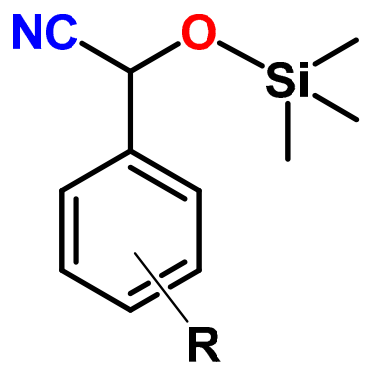

Scheme 1. Aldehyde cyanosilylation reaction with trimethylsilyl cyanide (TMSCN).

Under optimized conditions, a combination of benzaldehyde $(0.105 \mathrm{~g}, 1.0 \mathrm{mmol})$, trimethylsilyl cyanide ( $250 \mu \mathrm{L}, 2 \mathrm{mmol})$ and catalyst $(10.2 \mathrm{mg}$ for 1 and $10.8 \mathrm{mg}$ of 2; $2.0 \mathrm{~mol} \%$ ) was placed in a Pyrex tube covered with a Teflon cap and stirred at $50{ }^{\circ} \mathrm{C}$, under microwave irradiation ( $5 \mathrm{~W}$ ), for $1.5 \mathrm{~h}$, under solvent-free conditions. The desired product was identified by ${ }^{1} \mathrm{H}$ NMR spectroscopy (Supplementary Materials Figure S4), and the product yield was calculated, using the same procedure as reported in the literature [21].

We carried out the reactions in the presence of different solvents, such as $\mathrm{MeOH}$, $\mathrm{CHCl}_{3}, \mathrm{CH}_{3} \mathrm{CN}$ or THF, and in the absence of any solvent. Solvent-free conditions show the maximum catalytic activity, leading to a product yield of $97 \%$ or $85 \%$ for coordination polymer 1 or 2 , respectively (entries 1 and 2, Table 1). The use of other solvents leads to lower yields in the range of $57-81 \%$ for $\mathbf{1}$ (entries $3-6$, Table 1 and Figure $5 \mathrm{~B}$ ) and $41-76 \%$ for 2 (entries 7-10, Table 1 and Figure 5B). Performing the reaction in $\mathrm{CH}_{3} \mathrm{CN}$ gives the lowest yield of $57 \%$ or $41 \%$ for compound 1 or 2 , respectively. These observations are consistent with the competition of the solvent with the aldehyde substrate for the coordination to the metal.

Table 1. Cyanosilylation of benzaldehyde with trimethylsilyl cyanide (TMSCN) with coordination polymer 1 or 2 as catalyst ${ }^{\text {a }}$.

\begin{tabular}{|c|c|c|c|c|c|}
\hline Entry & Catalyst & $\begin{array}{c}\text { Temperature } \\
\left({ }^{\circ} \mathrm{C}\right)\end{array}$ & $\begin{array}{l}\text { Catalyst } \\
\text { Amount } \\
(\mathrm{mol} \%)\end{array}$ & Solvent & Yield $^{b}(\%)$ \\
\hline 1 & 1 & 50 & 2.0 & Solvent free & 97 \\
\hline 2 & 2 & 50 & 2.0 & Solvent free & 85 \\
\hline 3 & 1 & 50 & 2.0 & $\mathrm{MeOH}$ & 78 \\
\hline 4 & 1 & 50 & 2.0 & $\mathrm{CHCl}_{3}$ & 67 \\
\hline 5 & 1 & 50 & 2.0 & $\mathrm{CH}_{3} \mathrm{CN}$ & 57 \\
\hline 6 & 1 & 50 & 2.0 & THF & 81 \\
\hline 7 & 2 & 50 & 2.0 & $\mathrm{MeOH}$ & 55 \\
\hline 8 & 2 & 50 & 2.0 & $\mathrm{CHCl}_{3}$ & 43 \\
\hline 9 & 2 & 50 & 2.0 & $\mathrm{CH}_{3} \mathrm{CN}$ & 41 \\
\hline 10 & 2 & 50 & 2.0 & THF & 76 \\
\hline 11 & 1 & 50 & 1.0 & Solvent free & 52 \\
\hline 12 & 1 & 50 & 5.0 & Solvent free & 98 \\
\hline 13 & 2 & 50 & 1.0 & Solvent free & 30 \\
\hline 14 & 2 & 50 & 5.0 & Solvent free & 85 \\
\hline 15 & 1 & 25 & 2.0 & Solvent free & 32 \\
\hline 16 & 1 & 40 & 2.0 & Solvent free & 81 \\
\hline 17 & 1 & 60 & 2.0 & Solvent free & 96 \\
\hline 18 & 2 & 25 & 2.0 & Solvent free & 25 \\
\hline 19 & 2 & 40 & 2.0 & Solvent free & 80 \\
\hline 20 & 2 & 60 & 2.0 & Solvent free & 84 \\
\hline 21 & Blank & 50 & - & Solvent free & 10 \\
\hline 22 & $\mathrm{H}_{2} \mathrm{~L}$ & 50 & 2.0 & Solvent free & 18 \\
\hline 23 & $\mathrm{Zn}\left(\mathrm{NO}_{3}\right)_{3} \cdot 6 \mathrm{H}_{2} \mathrm{O}$ & 50 & 2.0 & Solvent free & 28 \\
\hline 24 & $\mathrm{Cd}\left(\mathrm{NO}_{3}\right)_{3} \cdot 4 \mathrm{H}_{2} \mathrm{O}$ & 50 & 2.0 & Solvent free & 23 \\
\hline
\end{tabular}

a Reaction conditions (unless stated otherwise): benzaldehyde $(1 \mathrm{mmol}), 2.0 \mathrm{~mol} \%$ (relative to the aldehyde) of catalyst, trimethylsilyl cyanide $(250 \mu \mathrm{L}, 2 \mathrm{mmol}), 1.5 \mathrm{~h}$ reaction time, at $50{ }^{\circ} \mathrm{C} .{ }^{\mathrm{b}}$ Calculated by ${ }^{1} \mathrm{H}-\mathrm{NMR}$ as the number of moles of final product 2-phenyl-2-((trimethylsilyl)oxy)acetonitrile per mole of aldehyde X 100 . 


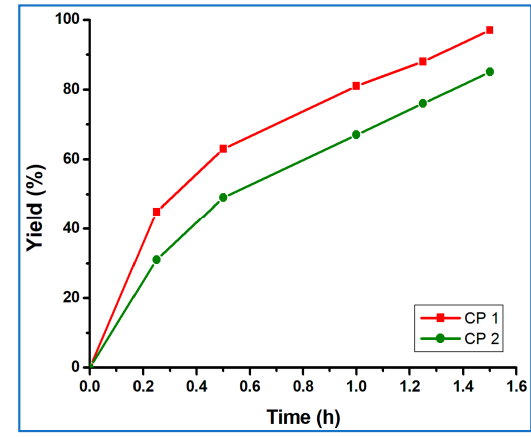

(A)

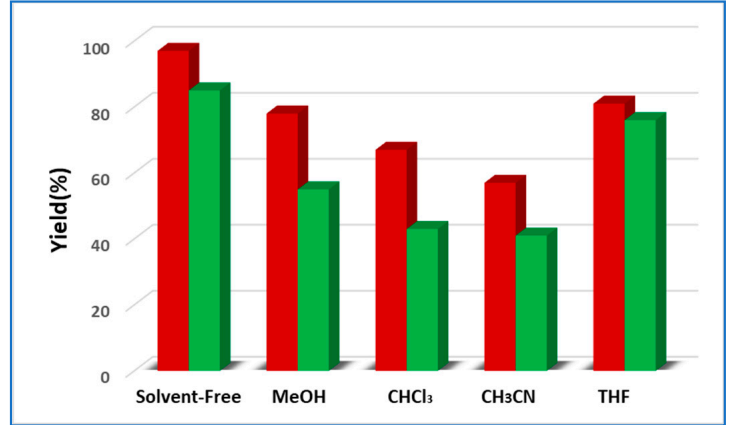

(B)

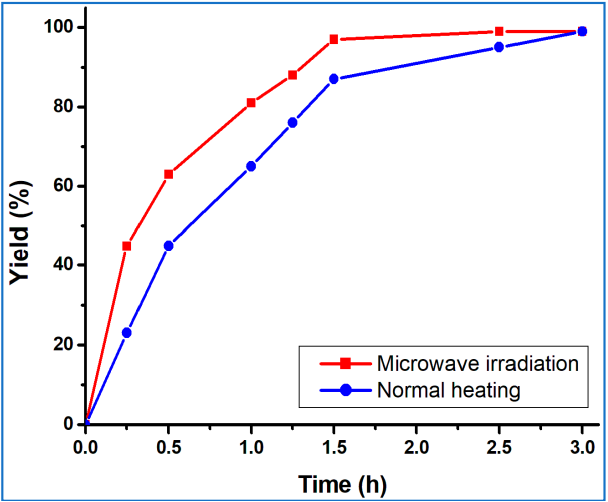

(C)

Figure 5. (A) Plot of yield vs. time for the microwave-assisted solvent-free cyanosilylation reaction of benzaldehyde, catalyzed by $\mathbf{1}$ or $\mathbf{2}$. (B) Yield of cyanosilylation of benzaldehyde in different solvents catalyzed by compounds $\mathbf{1}$ (red pillar) and $\mathbf{2}$ (green pillar). (C) Plots of yield vs. time for the microwave-assisted (red line) and normal-heating (blue line) solvent-free cyanosilylation reaction of benzaldehyde, catalyzed by 1 .

In order to optimize the catalyst loading, we changed the catalyst amount from 1.0 to $2.0 \mathrm{~mol} \%$ and observed a high enhancement of the product yield from 52 to $97 \%$ for 1 (entries 11 and 1, Table 1) or from 30 to $85 \%$ for 2 (entries 13 and 2, Table 1), but an additional increase of that amount (up to $5 \%$ ) resulted only in an almost undetected yield improvement for $\mathbf{1}$ (entry 12, Table 1) and in no yield change for $\mathbf{2}$ (entry 14, Table 1). Thus, the optimal catalyst amount was considered as $2 \mathrm{~mol} \%$ (relative to the aldehyde).

We also carried out the cyanosilylation reaction at different temperatures, to examine the effect of temperature. We obtained only $32 \%$ or $25 \%$ of product yield upon performing the reaction at room temperature $\left(25^{\circ} \mathrm{C}\right)$ (entry 15 or 18, Table 1$)$, using 1 or 2 as catalyst, respectively. Increasing the reaction temperature from 25 to $50{ }^{\circ} \mathrm{C}$ results in an yield increase to $97 \%$ or $85 \%$ for 1 or 2 (entry 1 or 2), respectively. Further increase in the temperature to $60^{\circ} \mathrm{C}$ did not improve the reaction yield (entries 17 and 20, Table 1).

A blank test was performed with benzaldehyde and TMSCN without any catalyst and resulted in only $10 \%$ yield of the final product after $1.5 \mathrm{~h}$ (entry 21 , Table 1 ). We also checked the cyanosilylation reaction with zinc nitrate, cadmium nitrate and the free ligand $\left(\mathrm{H}_{2} \mathrm{~L}\right)$ and the obtained reaction yields are within 18-23\% (entries 22-24, Table 1). Thus, the optimized reaction conditions for the cyanosilylation of the aldehyde with TMSCN concern $2 \mathrm{~mol} \%$ of the coordination polymer catalyst at $50{ }^{\circ} \mathrm{C}$ without any solvent. Under the optimized reaction conditions our coordination polymers 1 and 2 produce $97 \%$ and $85 \%$ of final product yields after $1.5 \mathrm{~h}$ under microwave irradiation, respectively. They correspond to a turnover number (TON) of 48.5 and 42.5 , and a turnover frequency (TOF) of 32.3 and $28.3 \mathrm{~h}^{-1}$.

After further spreading the reaction time to $2.5 \mathrm{~h}$, the final product yield increased up to $99 \%$ in the case of $\mathbf{1}$ or $87 \%$ for compound $\mathbf{2}$, but the TOF value decreases markedly (from $32.3 \mathrm{~h}^{-1}$ to $19.4 \mathrm{~h}^{-1}$ for $\mathbf{1}$ and from $28.3 \mathrm{~h}^{-1}$ to $17.0 \mathrm{~h}^{-1}$ for 2 ). The yield vs. time plots 
for the solvent-free cyanosilylation reaction of benzaldehyde and TMSCN catalyzed by 1 or $\mathbf{2}$ is presented in Figure 5A. We also performed the same reaction under normal heating conditions, instead of microwave, and the product yield was only $87 \%$ for compound 1 after $1.5 \mathrm{~h}$, and it took $3 \mathrm{~h}$ to reach $99 \%$ (Figure $5 \mathrm{~B}$ ). Thus, the use of microwave irradiation accelerated the reaction quite significantly.

We also tested the activity of our catalysts $\mathbf{1}$ and $\mathbf{2}$ towards different substituted aromatic aldehydes. The aromatic aldehydes containing strong electron-withdrawing groups, such as nitro, bromo and chloro, exhibit the highest yields in the range of 95-99\% for 1 and $89-96 \%$ for 2 (entries 1-4, Table 2). In contrast, the aldehydes containing electrondonating substituent, such as methyl or methoxy, display lower yields $58-75 \%$ (entries 7 and 8 , Table 2). The meta- and para-hydroxy substituted aldehydes show moderate reactivity and produce the corresponding cyanohydrin derivatives within the yield range of $67-91 \%$ (entries 5 and 6, Table 2), being also above the corresponding yields for the aldehydes with eletron-donor substituents. These behaviors are in accord with the expected effect of the substituent on the electrophilic character of the aldehyde $\mathrm{CHO}$ carbon to undergo attack by the cyano group of TMSCN.

Table 2. Cyanosilylation of different substituted aldehydes with trimethylsilyl cyanide (TMSCN) with catalyst 1 or 2 a.

\begin{tabular}{cccc}
\hline Entry & Reactant & Yield $^{\mathbf{b}} \mathbf{( \% )}$ with $\mathbf{1}$ & Yield $^{\mathbf{b}} \mathbf{( \% )}$ with $\mathbf{2}$ \\
\hline 1 & 4-Nitrobenzaldehyde & $>99$ & 96 \\
2 & 3-Nitrobenzaldehyde & 98 & 95 \\
3 & 4-Bromobenzaldehyde & $>99$ & 94 \\
4 & 4-Chlorobenzaldehyde & 95 & 89 \\
5 & 4-Hydroxybenzaldehyde & 91 & 75 \\
6 & 3-Hydroxybenzaldehyde & 88 & 67 \\
7 & 4-Methoxybenzaldehyde & 75 & 64 \\
8 & 4-Methylbenzaldehyde & 71 & 58 \\
\hline
\end{tabular}

a Reaction conditions: aldehyde ( $1 \mathrm{mmol})$, trimethylsilyl cyanide $(250 \mu \mathrm{L}, 2 \mathrm{mmol}), 2.0 \mathrm{~mol} \%$ of catalyst 1 or 2 for $1.5 \mathrm{~h}$ at $50{ }^{\circ} \mathrm{C}$. ${ }^{\mathrm{b}}$ Calculated by ${ }^{1} \mathrm{H}$ NMR.

The recyclability of the catalysts 1 and 2 was also tested. At the end of a reaction cycle, the catalyst was separated by centrifugation, washed with $\mathrm{CH}_{2} \mathrm{Cl}_{2}$ and dried before recycling it. It could be successfully recycled at least for four consecutive cycles, without considerably losing its activity, as shown in Figure 6B.

To check the leaching and heterogeneity of our catalysts, we separated the catalyst by centrifugation after $0.5 \mathrm{~h}$ and kept the catalyst-free reaction mixture under the same environment for $1 \mathrm{~h}$ more. After elimination of the solid catalyst 1 or $\mathbf{2}$ from the reaction mixture, no perceptible rise in the yield was observed (Figure 6A, blue and green dotted lines), which substantiates the absence of leaching and the heterogeneous nature of the catalyst. FTIR and powder X-ray diffraction analyses of the catalyst before and after the catalysis reaction were performed, to check the structural integrity of our catalysts $\mathbf{1}$ and 2, and no significant changes in their patterns were observed, as shown in Supplementary Materials Figure S2 and S3. These results support that the structures of the catalysts 1 and 2 remain intact after the catalytic reaction. 


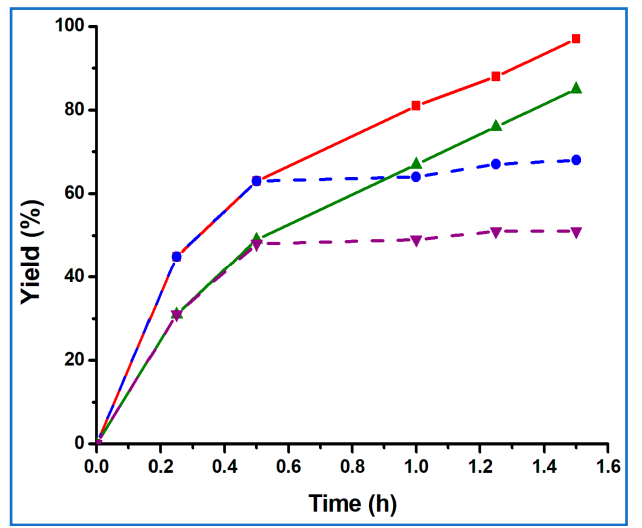

(A)

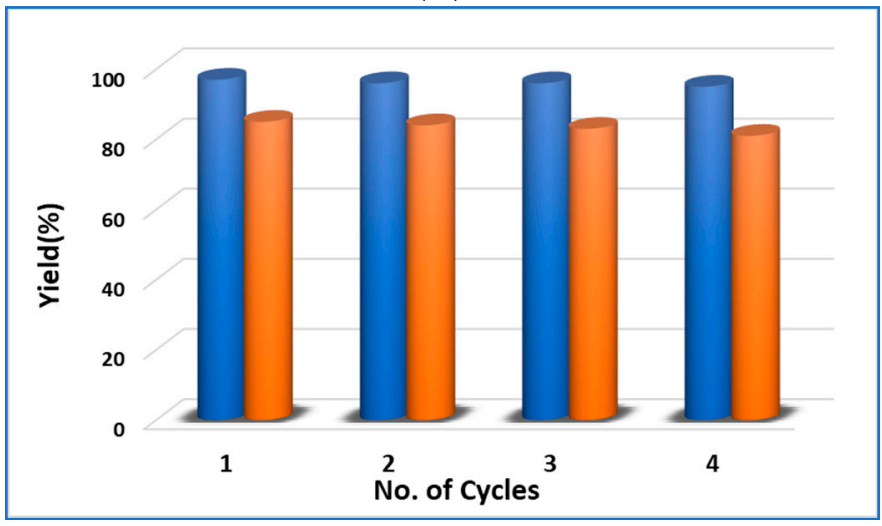

(B)

Figure 6. (A) Plots of product yield vs. time for the solvent-free cyanosilylation reaction, catalyzed by $\mathbf{1}$ (purple line) and $\mathbf{2}$ (red line) (blue dotted line indicates the catalyst $\mathbf{1}$ removal after $0.5 \mathrm{~h}$ and the green dotted line concerns the catalyst 2 removal after $0.5 \mathrm{~h}$ ). (B) Effect of the catalyst recycling on the final product yield (blue pillars for compound $\mathbf{1}$ and brown pillars for compound 2).

A comparison of the catalytic activity, towards the cyanosilylation of aldehydes with TMSCN, of our catalyst $\mathbf{1}$ with other reported coordination polymers is shown in Table 3. Our catalyst appears to be more efficient for such a reaction. For example, the cyanosilylation reaction of benzaldehyde and TMSCN at $50{ }^{\circ} \mathrm{C}$, under solvent-free conditions catalyzed by $[\operatorname{Pr}(3,5-\mathrm{DSB})(\mathrm{Phen})]_{\mathrm{n}}$ produce a yield of $78 \%$ after $3 \mathrm{~h}$ reaction time (entry 2 , Table 3) [25]. The heterometallic CP $\left[\left\{\mathrm{Co}_{0.6} \mathrm{Ni}_{1.4}\left(\mathrm{H}_{2} \mathrm{O}\right)_{2}(\mathrm{Bpe})_{2}\right\}\left(\mathrm{V}_{4} \mathrm{O}_{12}\right)\right] \cdot 4 \mathrm{H}_{2} \mathrm{O} \cdot$ Bpe gives a yield of $77 \%$, at $50{ }^{\circ} \mathrm{C}$, for $16 \mathrm{~h}$, under solvent-free conditions (entry 3, Table 3) [26]. Another heterometallic coordination polymer, [NaCu$(2,4-\mathrm{HPdc})(2,4-\mathrm{Pdc})]$, catalyzes the same reaction also under solvent-free conditions, for $24 \mathrm{~h}$ reaction time, producing an yield of $85 \%$ (entry 4, Table 3) [27]. Moreover, the mononuclear Sn(II) complex of 3-amino-2pyrazinecarboxylate gives a reaction yield of $75 \%$, at $50{ }^{\circ} \mathrm{C}$, after $4 \mathrm{~h}$ (entry 5 , Table 3) [28]. In this context, our catalyst 1 also leads to a $97 \%$ yield under solvent-free condition, at 50 ${ }^{\circ} \mathrm{C}$, after $1.5 \mathrm{~h}$ reaction time (entry 1 , Table 3 ). Therefore, our catalyst produces a higher product yield, in a shorter time, under solvent-free conditions. 
Table 3. A comparison of catalytic activity of different reported coordination polymers in the cyanosilylation of aldehydes with trimethylsilyl cyanide (TMSCN).

\begin{tabular}{|c|c|c|c|c|c|}
\hline Entry & Catalyst & Solvent/Temp/Time & Aldehyde & Yield (\%) & Reference \\
\hline 1 & 1 & Solvent free $/ 50^{\circ} \mathrm{C} / 1.5 \mathrm{~h}$ & Benzaldehyde & 97 & This work \\
\hline 2 & {$[\operatorname{Pr}(3,5-\mathrm{DSB})(\text { Phen })]_{\mathrm{n}}$} & Solvent free $/ 50^{\circ} \mathrm{C} / 3 \mathrm{~h}$ & Benzaldehyde & 78 & {$[23]$} \\
\hline 3 & {$\left[\left\{\mathrm{Co}_{0.6} \mathrm{Ni}_{1.4}\left(\mathrm{H}_{2} \mathrm{O}\right)_{2}(\mathrm{Bpe})_{2}\right\}\left(\mathrm{V}_{4} \mathrm{O}_{12}\right)\right] \cdot 4 \mathrm{H}_{2} \mathrm{O} \cdot \mathrm{Bpe}$} & Solvent free $/ 50^{\circ} \mathrm{C} / 16 \mathrm{~h}$ & Benzaldehyde & 77 & {$[24]$} \\
\hline 5 & {$\left[\mathrm{Sn}(\mathrm{L} 1)_{2}\right]$} & Solvent free $/ 50^{\circ} \mathrm{C} / 4 \mathrm{~h}$ & Benzaldehyde & 75 & [26] \\
\hline 6 & 1 & $\mathrm{THF} / 50^{\circ} \mathrm{C} / 1.5 \mathrm{~h}$ & Benzaldehyde & 81 & This work \\
\hline 7 & {$\left[\mathrm{~Pb}(\mathrm{~L} 1)_{2}\right]_{2}$} & $\mathrm{DCM} / 50{ }^{\circ} \mathrm{C} / 6 \mathrm{~h}$ & Benzaldehyde & 97 & [27] \\
\hline 8 & {$\left[\mathrm{Cu}_{3}(\text { benzenetricarboxylate })_{2}\right]_{\mathrm{n}}$} & pentane $/ 40^{\circ} \mathrm{C} / 72 \mathrm{~h}$ & Benzaldehyde & 57 & [28] \\
\hline 10 & $\left\{\left[\mathrm{Zn}(\mathrm{dpe})\left(\mu-\mathrm{OOCCH}_{3}\right)_{2}\right]\left(\mathrm{H}_{2} \mathrm{O}\right)\right\}_{n}$ & $\mathrm{DCM} / \mathrm{RT} / 24 \mathrm{~h}$ & Benzaldehyde & 14 & {$[30]$} \\
\hline 11 & $\begin{array}{c}\left\{\left[\mathrm{Zn}_{3}\left(4,4^{\prime}-\text { bpy }\right)_{4}(\mu-\right.\right. \\
\left.\left.\left.\mathrm{O}_{2} \mathrm{CCH}_{2} \mathrm{CH}_{3}\right)_{4}\right]\left(\mathrm{ClO}_{4}\right)_{2}\left(4,4^{\prime}-\text { bpy }\right)_{2}\left(\mathrm{H}_{2} \mathrm{O}\right)_{4}\right\}_{\mathrm{n}}\end{array}$ & $\mathrm{DCM} / \mathrm{RT} / 24 \mathrm{~h}$ & Benzaldehyde & 22 & {$[31]$} \\
\hline
\end{tabular}

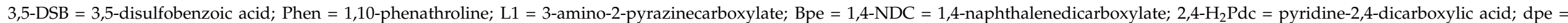
1,2-bis(4-pyridyl)ethene; $4,4^{\prime}$-bpy $=4,4^{\prime}$-bipyridine. 
Moreover, our catalyst 1 also shows a high efficiency in comparison to other reported coordination polymers, upon performing the cyanosilylation of benzaldehyde with TMSCN in the presence of a solvent (yield of $81 \%$, in THF at $50{ }^{\circ} \mathrm{C}$ after $1.5 \mathrm{~h}$, entry 6 , Table 3 ). For example, the dinuclear $\mathrm{Pb}$ (II)-3-amino-2-pyrazinecarboxylate complex produces the reaction yield of $97 \%$, at $50{ }^{\circ} \mathrm{C}$, in DCM, after $6 \mathrm{~h}$, a higher reaction time than our catalyst (entry 7, Table 3) [29]. An overall reaction yield of $57 \%$ after $48 \mathrm{~h}$ at $40{ }^{\circ} \mathrm{C}$ was obtained by using the $3 \mathrm{D}\left[\mathrm{Cu}_{3} \text { (benzenetricarboxylate) }{ }_{2}\right]_{n}$ MOF as catalyst (entry 8, Table 3) [30]. The 3D coordination polymer $\left[\mathrm{Cd}_{2}(1,4-\mathrm{NDC})_{2}(\mathrm{DMF})_{2}\right]_{\mathrm{n}}$ catalyzes the cyanosilylation of 4-nitrobenzaldehyde with an overall yield of $49 \%$ after $72 \mathrm{~h}$ at $50{ }^{\circ} \mathrm{C}$ (entry 9, Table 3) [31]. Moreover, the $\mathrm{Zn}(\mathrm{II})$ coordination polymers $\left\{\left[\mathrm{Zn}(\mathrm{dpe})\left(\mu-\mathrm{OOCCH}_{3}\right)_{2}\right]\left(\mathrm{H}_{2} \mathrm{O}\right)\right\}_{\mathrm{n}}$ and $\left\{\left[\mathrm{Zn}_{3}\left(4,4^{\prime} \text {-bpy }\right)_{4}\left(\mu-\mathrm{O}_{2} \mathrm{CCH}_{2} \mathrm{CH}_{3}\right)_{4}\right]\left(\mathrm{ClO}_{4}\right)_{2}\left(4,4^{\prime}-\text { bpy }\right)_{2}\left(\mathrm{H}_{2} \mathrm{O}\right)_{4}\right\}_{n}$ produce an yield of $14 \%$ and $22 \%$ upon performing the reaction in DCM, at room temperature, after $24 \mathrm{~h}$, respectively (entries 10 and 11, Table 3) [32,33].

Based on our previous reports, a similar plausible catalytic reaction mechanism is proposed, wherein a $\mathrm{Zn}$ (II) center activates the aldehyde carbonyl group and trimethylsilyl cyanide with promotion of the nucleophilic attack of the $\mathrm{CN}$ group to the carbonyl carbon, leading to the construction of a $\mathrm{C}-\mathrm{C}$ bond and thus to the cyanohydrin.

\section{Materials and Methods}

The synthesis of the ligand and coordination polymers were performed at a relatively high temperature. The chemicals were used as received from commercial sources. Bruker Vertex 70 instrument was used to record the FTIR spectra $\left(4000-400 \mathrm{~cm}^{-1}\right)$ in $\mathrm{KBr}$ pellets. The ${ }^{1} \mathrm{H}$ NMR spectra for the ligand were recorded at room temperature, on a Bruker Avance $\mathrm{II}+300$ (UltraShield ${ }^{\mathrm{TM}}$ Magnet) spectrometer, operating at $300.130 \mathrm{MHz}$, and the chemical shifts are reported in ppm, using tetramethylsilane as the internal reference. TGA was carried out with a Perkin-Elmer Instrument system (STA6000), at a heating rate of $5{ }^{\circ} \mathrm{C}$ $\mathrm{min}^{-1}$, under a dinitrogen atmosphere. $\mathrm{C}, \mathrm{H}$ and $\mathrm{N}$ elemental analyses for the coordination polymers were carried out by the Microanalytical Service of the Instituto Superior Técnico. A D8 Advance Bruker AXS (Bragg Brentano geometry) diffractometer, with Cu-radiation $(\mathrm{Cu} \mathrm{K} \alpha, \lambda=1.5406 \AA$ ), was used to collect powder X-ray data (PXRD), operated at $40 \mathrm{kV}$ and $40 \mathrm{~mA}$. The typical data-collection range was between $5^{\circ}$ and $40^{\circ}$, and a flat plate configuration was used.

\subsection{Synthesis of 5-\{(pyren-4-ylmethyl)amino\}isophthalic Acid $\left(\mathrm{H}_{2} \mathrm{~L}\right)$}

The pro-ligand $\mathrm{H}_{2} \mathrm{~L}$ was synthesized, using a two-step reaction. In the first step, 1-pyrenecarboxaldehyde $(0.576 \mathrm{~g}, 2.5 \mathrm{mmol})$ and 5-aminoisophtalic acid $(0.453 \mathrm{~g}, 2.5 \mathrm{mmol})$ were placed in a round bottom flask, and then dry methanol $(25 \mathrm{~mL})$ was added. After stirring overnight at room temperature, a yellow suspension was obtained. The solution was filtered, and the yellow solid was collected on filter paper, which was further washed several times, using fresh methanol. The obtained compound was dried in air and used in next step, without purification.

In the second step, the isolated compound $(1.58 \mathrm{~g}, 4 \mathrm{mmol})$ was dissolved in $25 \mathrm{~mL}$ of methanol, and $\mathrm{NaBH}_{4}$ was gradually added to the suspension, until a colorless solution was obtained. Afterwards, the reaction mixture was left, stirring overnight, at room temperature. Upon completion, the methanol was evaporated, and $10 \mathrm{~mL}$ water was added into it, followed by the acidification until $\mathrm{pH}=2$, with a diluted solution of $\mathrm{HCl}$. The obtained white solid product $\mathrm{H}_{2} \mathrm{~L}$ was isolated by filtration and thoroughly washed with water. Yield: 89\%. FTIR (KBr, cm ${ }^{-1}$ ): 3843 (wbr), 3381 (s), $3043(\mathrm{~m}), 2873(\mathrm{~m}), 2590$ (m), 2509 (m), $2360(\mathrm{w}), 1932(\mathrm{w}), 1681$ (s, vasym $\mathrm{C}=\mathrm{O}), 1600(\mathrm{~s}, \vee \mathrm{C}=\mathrm{C}), 1542(\mathrm{~s}, \vee \mathrm{C}=\mathrm{C})$, $1504(\mathrm{~s}, v \mathrm{C}=\mathrm{C}), 1425\left(\mathrm{~s}, v_{\mathrm{sym}} \mathrm{C}=\mathrm{O}\right), 1330(\mathrm{~s}), 1271(\mathrm{~s}), 1244(\mathrm{~s}), 1137(\mathrm{~m}), 1083(\mathrm{~m}), 997(\mathrm{w})$, $964(\mathrm{w}), 950(\mathrm{w}), 889(\mathrm{w}), 844(\mathrm{~s}), 759(\mathrm{~s}), 711(\mathrm{~s}), 694(\mathrm{~s}) ;{ }^{1} \mathrm{H}-\mathrm{NMR}$ (DMSO-d $\left.{ }^{6}\right): \delta 8.48-8.45$ $(1 \mathrm{H}, \mathrm{m}, \mathrm{Ar}-\mathrm{H}), 8.31-8.26(4 \mathrm{H}, \mathrm{m}, \mathrm{Ar}-\mathrm{H}), 8.25-8.15(4 \mathrm{H}, \mathrm{m}, \mathrm{Ar}-\mathrm{H}), 7.74(1 \mathrm{H}, \mathrm{s}, \mathrm{Ar}-\mathrm{H}), 7.43(2 \mathrm{H}$, $\mathrm{s}, \mathrm{Ar}-\mathrm{H}), 6.78(1 \mathrm{H}, \mathrm{s}, \mathrm{N}-\mathrm{H}), 5.05\left(2 \mathrm{H}, \mathrm{s},-\mathrm{CH}_{2}\right)$. Anal. Calcd. for $\mathrm{C}_{25} \mathrm{H}_{19} \mathrm{NO}_{4}(\mathrm{M}=397.42)$ : $\mathrm{C}$, 75.55; H, 4.82; N, 3.52. Found: C, 75.52; H, 4.65; N, 3.61 . 


\subsection{Synthesis of the Coordination Polymer $\left[\mathrm{Zn}(\mathrm{L})\left(\mathrm{H}_{2} \mathrm{O}\right)_{2}\right]_{n} \cdot n\left(\mathrm{H}_{2} \mathrm{O}\right)(\mathbf{1})$}

A mixture of $\mathrm{H}_{2} \mathrm{~L}(10 \mathrm{mg}, 0.025 \mathrm{mmol})$ and $\mathrm{Zn}\left(\mathrm{NO}_{3}\right)_{2} \cdot 6 \mathrm{H}_{2} \mathrm{O}(7.4 \mathrm{mg}, 0.025 \mathrm{mmol})$ in $2 \mathrm{~mL}$ EtOH was prepared, and afterwards, $0.5 \mathrm{~mL}$ of $\mathrm{NH}_{4} \mathrm{OH}$ (30\% aqueous solution) was added. This mixture was then put into an $8 \mathrm{~mL}$ glass vessel, sealed and heated at 75 ${ }^{\circ} \mathrm{C}$, for $48 \mathrm{~h}$. Then the reaction mixture was cooled to room temperature, giving colorless crystals of 1. FTIR ( $\left.\mathrm{KBr}, \mathrm{cm}^{-1}\right) 3381$ (mbr), $2914(\mathrm{w}), 1640\left(\mathrm{~s}, v_{\mathrm{asym}} \mathrm{C}=\mathrm{O}\right), 1561$ (s, v C=C), $1504(\mathrm{w}), 1421(\mathrm{~s}, v \mathrm{C}=\mathrm{C}), 1352\left(\mathrm{~s}, v_{\mathrm{sym}} \mathrm{C}=\mathrm{O}\right), 1322(\mathrm{~m}), 1274(\mathrm{~m}), 1199(\mathrm{~s}), 1109(\mathrm{w}), 1076(\mathrm{w})$, $979(\mathrm{w}), 846(\mathrm{~s}), 828(\mathrm{~s}), 781(\mathrm{~m}), 712(\mathrm{w})$. Anal. Calcd. for $\mathrm{C}_{25} \mathrm{H}_{21} \mathrm{NO}_{7} \mathrm{Zn}(\mathrm{M}=512.80)$ : $\mathrm{C}$, 58.55; H, 4.13; N, 2.73. Found: C, 58.23; H, 3.86; N, 2.42.

\subsection{Synthesis of the Coordination Polymer $\left[\mathrm{Cd}(\mathrm{L})\left(\mathrm{H}_{2} \mathrm{O}\right)\right]_{n} \cdot n\left(\mathrm{H}_{2} \mathrm{O}\right)$ (2)}

$\mathrm{Cd}\left(\mathrm{NO}_{3}\right)_{2} \cdot 6 \mathrm{H}_{2} \mathrm{O}(8 \mathrm{mg}, 0.025 \mathrm{mmol})$ and $\mathrm{H}_{2} \mathrm{~L}(10 \mathrm{mg}, 0.025 \mathrm{mmol})$ were dissolved in 2 $\mathrm{mL}$ of DMF: $\mathrm{H}_{2} \mathrm{O}(2: 1, \mathrm{v} / \mathrm{v})$ mixture, and the obtained system was sealed in a capped glass vessel and heated to $75^{\circ} \mathrm{C}$, for $48 \mathrm{~h}$. The mixture was then cooled gradually, and colorless crystals of the coordination polymer 2 were obtained. FTIR $\left(\mathrm{KBr}, \mathrm{cm}^{-1}\right) 3320(\mathrm{mbr})$, $2934(\mathrm{w}), 1641$ (s, vasym C=O), $1572(\mathrm{~s}, \vee \mathrm{C}=\mathrm{C}), 1531(\mathrm{~s}), 1411(\mathrm{~s}, \vee \mathrm{C}=\mathrm{C}), 1370\left(\mathrm{~s}, v_{\mathrm{sym}} \mathrm{C}=\mathrm{O}\right)$, $1284(\mathrm{~s}), 1148(\mathrm{w}), 1080(\mathrm{w}), 1106(\mathrm{~m}), 906(\mathrm{w}), 840(\mathrm{~s}), 802(\mathrm{~s}), 779(\mathrm{~s}), 673(\mathrm{~m})$. Anal. Calcd. for $\mathrm{C}_{25} \mathrm{H}_{17} \mathrm{CdNO}_{6}(\mathrm{M}=539.82)$ : $\mathrm{C}, 55.62 ; \mathrm{H}, 3.17 ; \mathrm{N}, 2.59$. Found: $\mathrm{C}, 55.33 ; \mathrm{H}, 3.15 ; \mathrm{N}, 2.78$.

\subsection{Procedure for the Cyanosilylation Reaction of Aldehydes}

A mixture of an aromatic aldehyde ( $1 \mathrm{mmol})$, trimethylsilyl cyanide $(250 \mu \mathrm{L}, 2 \mathrm{mmol})$ and $2.0 \mathrm{~mol} \%$ catalyst (10.2 $\mathrm{mg}$ of $\mathbf{1}$ or $10.8 \mathrm{mg}$ of $\mathbf{2}$; relative to the aldehyde) was placed in a Pyrex tube. The tube was then put in the microwave reactor, and the reaction mixture was left, stirring under MW irradiation $(5 \mathrm{~W})$, at $50{ }^{\circ} \mathrm{C}$, in solvent-free conditions, for the desired time. The catalyst was then separated by centrifugation, and the reaction mixture was evaporated, using a rotary evaporator. Then the final product was dissolved in $\mathrm{CDCl}_{3}$ and analyzed by ${ }^{1} \mathrm{H}$ NMR (Supplementary Materials Figure S4).

\subsection{Crystal Structure Determinations}

X-ray quality single crystals of the coordination polymers $\mathbf{1}$ and $\mathbf{2}$ were placed in cryo-oil and mounted in a nylon loop, and the data collection was done by using a Bruker APEX-II PHOTON 100 diffractometer with graphite monochromated Mo-K $\alpha$ ( $\lambda$ 0.71069) radiation, at room temperature. Phi and omega scans $\left(0.5^{\circ}\right.$ per frame) were used for the data collection, and a full sphere of data was obtained. Bruker SMART [34] software was used to obtain cell parameters and refined the data by using Bruker SAINT [34] on all the observed reflections. By using the SADABS [35] program, the absorption corrections were performed. The crystal structures were solved by using the SIR 97 program and refined with SHELXL2014/6 [36]. Calculations were performed, using the WinGX System-Version 2014.1 [37]. The $\mathrm{H}$-atoms attached to $\mathrm{C}$ - and $\mathrm{N}$-atoms were introduced at geometrically calculated positions and encompassed in the refinement, using the riding-model approximation; $\mathrm{U}_{\text {iso }}(\mathrm{H})$ were defined as $1.2 \mathrm{U}_{\text {eq }}$ of the parent atoms for phenyl and $1.5 \mathrm{U}_{\text {eq }}$ of the parent atoms for the $\mathrm{O}$ - and $\mathrm{N}$-atoms. Least-square refinements with anisotropic thermal motion parameters for all the non-hydrogen atoms and isotropic ones for the residual atoms were employed. In Supplementary Materials Table S1, the crystallographic data are summarized; in Supplementary Materials Table S2, selected bond distances and angles are presented; and the hydrogen bonding interactions are presented in Supplementary Materials Table S3. The Cambridge Crystallographic Data Centre (CCDC) codes 2057313 and 2057314 contain the supplementary crystallographic data for this paper. These data can be obtained free of charge from The Cambridge Crystallographic Data Centre.

\section{Conclusions}

We synthesized and characterized two new coordination polymers, namely [ $\mathrm{Zn}(\mu-$ $\left.\left.1 \kappa O^{1}: 1 \kappa O^{2}-\mathrm{L}\right)\left(\mathrm{H}_{2} \mathrm{O}\right)_{2}\right]_{\mathrm{n}} \cdot \mathrm{n}\left(\mathrm{H}_{2} \mathrm{O}\right)(\mathbf{1})$ and $\left[\mathrm{Cd}\left(\mu_{4}-1 \kappa O^{1} O^{2}: 2 \kappa N: 3,4 \kappa O^{3}-\mathrm{L}\right)\left(\mathrm{H}_{2} \mathrm{O}\right)\right]_{\mathrm{n}} \cdot \mathrm{n}\left(\mathrm{H}_{2} \mathrm{O}\right)(2)$, constructed from 5-\{(pyren-4-ylmethyl)amino\}isophthalic acid $\left(\mathrm{H}_{2} \mathrm{~L}\right)$ with $\mathrm{Zn}\left(\mathrm{NO}_{3}\right)_{2} \cdot 6 \mathrm{H}_{2} \mathrm{O}$ 
and $\mathrm{Cd}\left(\mathrm{NO}_{3}\right)_{2} \cdot 4 \mathrm{H}_{2} \mathrm{O}$, respectively, under solvothermal reaction conditions. Single-crystal Xray diffraction analyses revealed that the coordination polymer $\mathbf{1}$ features a one-dimensional linear structure, whereas 2 presents a two-dimensional network. The presence of Lewis acid (metal ion) and basic (amine group) centers, as well as the insolubility in organic solvents, makes these CPs suitable for heterogeneous catalysis.

Thus, we tested the catalytic activities of these synthesized coordination polymers towards the cyanosilylation reaction of various aldehydes with TMSCN, under microwave irradiation. They show a high activity for such a reaction under solvent-free conditions, mainly the $\mathrm{Zn}$ (II)-coordination polymer (1), which is more active than the $\mathrm{Cd}(\mathrm{II})$ one (2), what may reflect the higher Lewis acidity of the $\mathrm{Zn}$ (II) center in the former than that of the $\mathrm{Cd}(\mathrm{II})$ site in the latter. However, the simpler 1D nature of $\mathbf{1}$ with more accessible metal centers, in comparison with the two-dimensional coordination polymer $\mathbf{2}$, can be another reason behind the higher catalytic efficiency of $\mathbf{1}$. We also demonstrated the heterogeneous nature, the stability and recyclability of the catalysts $\mathbf{1}$ and $\mathbf{2}$. They can be recycled at least four times, without losing activity appreciably. Moreover, the use of microwave irradiation in such a reaction reduces the reaction time significantly. This work provides further indication that coordination polymers constructed from simple ligands, bearing both Lewis acid and basic centers, can be applied as efficient heterogeneous catalysts in important types of reactions, such as that investigated herein.

Supplementary Materials: The following are available online, Figure S1: (A) $\pi \cdots \pi$ interactions (between pyrene rings) in coordination polymer 1, Figure S2: FT-IR spectra of catalysts 1 (A) and 2 (B) before (black) and after (red) the cyanosilylation reaction, Figure S3: PXRD spectra of catalysts 1 (A) and 2 (B) simulate (black), before (red) and after (blue) the cyanosilylation reaction, Figure S4: ${ }^{1} \mathrm{H}-\mathrm{NMR}$ spectra of solvent-free cyanosilylation of benzaldehyde with catalysts 1 (A) and 2 (B) in $\mathrm{CDCl}_{3}$ (entries 1 and 2, Table 1) (The protons are considered in the integrations are indicated in red colour), Table S1: Crystal data and structure refinement details for compounds 1-2, Table S2: Hydrogen bond geometry $\left(\AA,^{\circ}\right)$ in compounds $1-2$, Table S3: Selected bond distances $(\AA)$ and angles $\left({ }^{\circ}\right)$ for compounds $1-2$.

Author Contributions: A.K. designed the research strategy, ligand synthesis, catalytic studies, X-ray analysis and manuscript writing; E.P.S. synthesized compounds 1 and 2; A.P. performed NMR, catalytic studies and manuscript writing; A.J.L.P. and M.F.C.G.d.S. performed manuscript reading and correction. All authors have read and agreed to the published version of the manuscript.

Funding: This work was supported by the Fundação para a Ciência e Tecnologia (FCT), Portugal, project UIDB / 00100/2020 of Centro de Química Estrutural, and by the RUDN University Strategic Academic Leadership Program.

Institutional Review Board Statement: Not applicable.

Informed Consent Statement: Not applicable.

Data Availability Statement: Not applicable.

Acknowledgments: A. Karmakar and A. Paul express their gratitude to Instituto Superior Técnico and FCT for Scientific Employment contracts (Contrato Nos: IST-ID/107/2018 and IST-ID/197/2019), under Decree-Law no. 57/2016, of August 29. The authors also acknowledge the Portuguese NMR Network (IST-UL Centre) for access to the NMR facility. This work was also supported by the RUDN University Strategic Academic Leadership Program.

Conflicts of Interest: The authors declare no conflict of interest.

\section{References}

1. Zhang, Z.; Zaworotko, M.J. Template-directed synthesis of metal-organic materials. Chem. Soc. Rev. 2014, 43, 5444-5455. [CrossRef] [PubMed]

2. Karmakar, A.; Titi, H.M.; Goldberg, I. Coordination Polymers of 5-(2-Amino/Acetamido-4-carboxyphenoxy)-benzene-1,3-dioic Acids with Transition Metal Ions: Synthesis, Structure, and Catalytic Activity. Cryst. Growth Des. 2011, 11, 2621-2636. [CrossRef] 
3. Karmakar, A.; Martins, L.M.D.R.S.; Hazra, S.; Da Silva, M.F.C.G.; Pombeiro, A.J.L. Metal-Organic Frameworks with Pyridyl-Based Isophthalic Acid and Their Catalytic Applications in Microwave Assisted Peroxidative Oxidation of Alcohols and Henry Reaction. Cryst. Growth Des. 2016, 16, 1837-1849. [CrossRef]

4. Dhakshinamoorthy, A.; Li, Z.; Garcia, H. Catalysis and photocatalysis by metal organic frameworks. Chem. Soc. Rev. 2018, 47, 8134-8172. [CrossRef] [PubMed]

5. Karmakar, A.; Pombeiro, A.J.L. Recent advances in amide functionalized metal organic frameworks for heterogeneous catalyt-ic applications. Coord. Chem. Rev. 2019, 395, 86-129. [CrossRef]

6. Huang, Y.-B.; Liang, J.; Wang, X.-S.; Cao, R. Multifunctional metal-organic framework catalysts: Synergistic catalysis and tan-dem reactions. Chem. Soc. Rev. 2017, 46, 126-157. [CrossRef]

7. Jin, F.-Z.; Zhao, C.-C.; Ma, H.-C.; Chen, G.-J.; Dong, Y.-B. Homochiral BINAPDA-Zr-MOF for Heterogeneous Asymmetric Cyanosilylation of Aldehydes. Inorg. Chem. 2019, 58, 9253-9259. [CrossRef]

8. Karmakar, A.; Paul, A.; Mahmudov, K.T.; Da Silva, M.F.C.G.; Pombeiro, A.J.L. pH dependent synthesis of Zn(ii) and Cd(ii) coordination polymers with dicarboxyl-functionalized arylhydrazone of barbituric acid: Photoluminescence properties and catalysts for Knoevenagel condensation. New J. Chem. 2016, 40, 1535-1546. [CrossRef]

9. Dhakshinamoorthy, A.; Alvaro, M.; Garcia, H. Metal-organic frameworks as heterogeneous catalysts for oxidation reactions. Catal. Sci. Technol. 2011, 1, 856-867. [CrossRef]

10. Karmakar, A.; Oliver, C.L.; Roy, S.; Öhrström, L. The synthesis, structure, topology and catalytic application of a novel cub-anebased copper(ii) metal-organic framework derived from a flexible amido tripodal acid. Dalton Trans. 2015, 44, 10156-10165. [CrossRef]

11. Fan, Y.; Ren, Y.; Li, J.; Yu, C.; Jiang, H. Enhanced Activity and Enantioselectivity of Henry Reaction by the Postsynthetic Re-duction Modification for a Chiral Cu(salen)-Based Metal-Organic Framework. Inorg. Chem. 2018, 57, 11986-11994. [CrossRef]

12. Jiang, N.; Mallat, T.; Krumeich, F.; Baiker, A. Copper-based metal-organic framework for the facile ring-opening of epoxides. J. Catal. 2008, 257, 390-395. [CrossRef]

13. Karmakar, A.; Rúbio, G.M.D.M.; Guedes da Silva, M.F.C.; Ribeiro, A.P.C.; Pombeiro, A.J.L. ZnII and CdII MOFs based on an amidoisophthalic acid ligand: Synthesis, structure and catalytic application in transesterification. RSC Adv. 2016, 6, 89007-89018. [CrossRef]

14. Karmakar, A.; Soliman, M.M.A.; Rúbio, G.M.D.M.; Guedes da Silva, M.F.C.; Pombeiro, A.J.L. Synthesis and catalytic ac-tivities of a $\mathrm{Zn}$ (ii) based metallomacrocycle and a metal-organic framework towards one-pot deacetalization-Knoevenagel tandem reactions under different strategies: A comparative study. Dalton Trans. 2020, 49, 8075-8085. [CrossRef] [PubMed]

15. Brunel, J.-M.; Holmes, I.P. Chemically Catalyzed Asymmetric Cyanohydrin Syntheses. Angew. Chem. Int. Ed. 2004, 43, 2752-2778. [CrossRef]

16. Lacour, M.-A.; Rahier, N.J.; Taillefer, M. Mild and Efficient Trimethylsilylcyanation of Ketones Catalysed by PNP Chloride. Chem. A Eur. J. 2011, 17, 12276-12279. [CrossRef]

17. Zhang, Y.; Su, K.; Hao, M.; Liu, L.; Han, Z.-B.; Yuan, D. Two metal-organic frameworks based on pyridyl-tricarboxylate lig-ands as size-selective catalysts for solvent-free cyanosilylation reaction. CrystEngComm 2018, 20, 6070-6076. [CrossRef]

18. Wu, X.; Lin, Z.; He, C.; Duan, C. Catalytic performance of lanthanide molecular solids containing well-modified metal-organic octahedra. New J. Chem. 2011, 36, 161-167. [CrossRef]

19. Aguirre-Díaz, L.M.; Iglesias, M.; Snejko, N.; Gutiérrez-Puebla, E.; Monge, M.Á. Indium metal-organic frameworks as catalysts in solvent-free cyanosilylation reaction. CrystEngComm 2013, 15, 9562-9571. [CrossRef]

20. Hu, T.-P.; Zhao, Y.-Q.; Mei, K.; Lin, S.-J.; Wang, X.-P.; Sun, D. A novel silver(i)-Keggin-polyoxometalate inorganic-organic hy-brid: A Lewis acid catalyst for cyanosilylation reaction. CrystEngComm 2015, 17, 5947-5952. [CrossRef]

21. Kantam, M.L.; Mahendar, K.; Sreedhar, B.; Kumar, K.V.; Choudary, B.M. Cyanosilylation of Aldehydes and Ketones Cata-lyzed by Nanocrystalline Magnesium Oxide. Synth. Commun. 2008, 38, 3919-3936. [CrossRef]

22. Karmakar, A.; Soliman, M.M.A.; Alegria, E.C.B.A.; Rúbio, G.M.D.M.; Da Silva, M.F.C.G.; Pombeiro, A.J.L. A copperamidocarboxylate based metal organic macrocycle and framework: Synthesis, structure and catalytic activities towards microwave assisted alcohol oxidation and Knoevenagel reactions. New J. Chem. 2019, 43, 9843-9854. [CrossRef]

23. Karmakar, A.; Paul, A.; Rúbio, G.M.D.M.; Da Silva, M.F.C.G.; Pombeiro, A.J.L. Zinc(II) and Copper(II) Metal-Organic Frameworks Constructed from a Terphenyl-4,4"-dicarboxylic Acid Derivative: Synthesis, Structure, and Catalytic Application in the Cyanosilylation of Aldehydes. Eur. J. Inorg. Chem. 2016, 2016, 5557-5567. [CrossRef]

24. Yang, L.; Powell, D.R.; Houser, R.P. Structural variation in copper(i) complexes with pyridylmethylamide ligands: Structural analysis with a new four-coordinate geometry index, $\tau 4$. Dalton Trans. 2007, 955-964. [CrossRef]

25. D’Vries, R.F.; Iglesias, M.; Snejko, N.; Gutiérrez-Puebla, E.; Monge, M.A. Lanthanide Metal-Organic Frameworks: Searching for Efficient Solvent-Free Catalysts. Inorg. Chem. 2012, 51, 11349-11355. [CrossRef] [PubMed]

26. de Luis, R.F.; Karmele Urtiaga, M.; Mesa, J.L.; Larrea, E.S.; Iglesias, M.; Rojo, T.; Arriortua, M.I. Thermal Response, Cata-lytic Activity, and Color Change of the First Hybrid Vanadate Containing Bpe Guest Molecules. Inorg. Chem. 2013, 52, $2615-2626$. [CrossRef]

27. Larrea, E.S.; de Luis, R.F.; Orive, J.; Iglesias, M.; Arriortua, M.I. [NaCu(2,4-HPdc)(2,4-Pdc)] Mixed Metal-Organic Frame-work as a Heterogeneous Catalyst. Eur. J. Inorg. Chem. 2015, 28, 4699-4707. [CrossRef] 
28. Karmakar, A.; Hazra, S.; Rúbio, G.M.D.M.; Da Silva, M.F.C.G.; Pombeiro, A.J.L. Packing polymorphism in 3-amino-2pyrazinecarboxylate based tin(ii) complexes and their catalytic activity towards cyanosilylation of aldehydes. New J. Chem. 2018, 42, 17513-17523. [CrossRef]

29. Karmakar, A.; Hazra, S.; Da Silva, M.F.C.G.; Pombeiro, A.J.L. Synthesis, structure and catalytic application of lead(ii) complexes in cyanosilylation reactions. Dalton Trans. 2014, 44, 268-280. [CrossRef] [PubMed]

30. Schlichte, K.; Kratzke, T.; Kaskel, S. Improved synthesis, thermal stability and catalytic properties of the metal-organic framework compound $\mathrm{Cu}_{3}(\mathrm{BTC})_{2}$. Microporous Mesoporous Mater. 2004, 73, 81-88. [CrossRef]

31. Choi, I.-H.; Kim, Y.; Lee, D.N.; Huh, S. Three-dimensional cobalt(II) and cadmium(II) MOFs containing 1,4-naphthalenedicarboxylate: Catalytic activity of Cd-MOF. Polyhedron 2016, 105, 96-103. [CrossRef]

32. Phuengphai, P.; Youngme, S.; Chaichit, N.; Reedijk, J. New 3D supramolecular networks built from 1D and 2D frameworks via $\pi-\pi$ and H-bonding interactions: Topology and catalytic properties. Inorg. Chim. Acta 2013, 403, 35-42. [CrossRef]

33. Phuengphai, P.; Youngme, S.; Gamez, P.; Reedijk, J. Catalytic properties of a series of coordination networks: Cyanosilylation of aldehydes catalyzed by Zn(ii)-4,4'-bpy-carboxylato complexes. Dalton Trans. 2010, 39, 7936-7942. [CrossRef]

34. Bruker APEX2; Bruker AXS Inc.: Madison, WI, USA, 2012.

35. Sheldrick, G.M. SADABS. Program for Empirical Absorption Correction; University of Gottingen: Gottingen, Germany, 1996.

36. Sheldrick, G.M. Crystal structure refinement with SHELXL. Acta Cryst. 2015, 71, 3-8. [CrossRef]

37. Farrugia, L.J. WinGX and ORTEP for Windows: An update. J. Appl. Crystallogr. 2012, 45, 849-854. [CrossRef] 